\title{
An Ethnographic Examination of People's Reactions to State-Led COVID-19 Measures in Sierra Leone
}

\author{
Jess Jones $^{1}$ (D)
}

Accepted: 19 December 2020 / Published online: 1 February 2021

(c) European Association of Development Research and Training Institutes (EADI) 2021

\begin{abstract}
This paper explores how individuals - defined along lines of gender, age, life experience, financial capital and profession-experience and react in nuanced ways to the impacts of state-led COVID-19 measures, in Sierra Leone. The findings are based on ethnographic data collected from Makeni city and three rural communities in Bombali District, north Sierra Leone during the outbreak of COVID-19, between 23rd March and 6th May 2020. The findings show how state-led measures-indefinite district lockdown, three-day total lockdowns and mask wearing-were experienced and responded to in myriad ways, including adapting, not complying and resisting. The diverse ways members of society experience, react and shape the effects of internationally and nationally informed health policies during a global pandemic in Sierra Leone highlight the nuances of individual experience and agency in specific socio-political contexts. These findings contribute to the emerging Social Science debate on state-society relations in the COVID-19 pandemic response.
\end{abstract}

Keywords COVID-19 $\cdot$ Sierra Leone $\cdot$ Adaptive capacity $\cdot$ Non-compliance Passive resistance $\cdot$ Active resistance

\section{Résumé}

Cet article explore la façon dont les gens—qui sont définis selon leur sexe, leur âge, leur expérience de vie, leur capital financier et leur profession-vivent et réagissent de manière nuancée à l'impact des mesures anti-COVID-19 lancées par l'État en Sierra Leone. Les résultats sont issus de données ethnographiques collectées dans la ville de Makeni et dans trois communautés rurales du district de Bombali, au nord de la Sierra Leone, lors de l'épidémie de COVID-19, entre le 23 mars et le 6 mai 2020. Les résultats montrent comment les mesures prises par l'État-le confinement illimité du district, des confinements totaux de trois jours et le port du masque-ont été vécues et ont provoqué de multiples réactions, dont l'adaptation, le non-conformisme et la résistance. En Sierra Leone, les membres de la société vivent, réagissent

Jess Jones

jessjonesunimak@gmail.com

1 University of Makeni, Makeni, Sierra Leone 
et façonnent de diverses façons les effets des politiques de santé pendant une pandémie mondiale, politiques influencées par le contexte national et international. Ces diverses réactions mettent en lumière les nuances de l'expérience individuelle et du libre-arbitre dans des contextes sociopolitiques particuliers. Ces résultats contribuent au débat émergent en sciences sociales sur les relations entre l'État et la société dans la réponse à la pandémie de COVID-19.

JEL classification $\mathrm{I} 18 \cdot \mathrm{I} 12 \cdot \mathrm{I} 30 \cdot \mathrm{Z} 10$

\section{Introduction/Background}

When COVID-19 broke out in the Wuhan, Hubei Province of China, in December 2019 and began to spread across the world, there was a certain amount of anxiety in Sierra Leone, enhanced by the country's previous experience of Ebola (2014-2015). The outbreak of Ebola revealed the country's inability to effectively deal with such a health emergency, at least in part due to the country's weak health system (Kieny et al. 2014; O'Hare 2015; Shoman et al. 2017; Agyeman et al. 2020). The Ebola epidemic had significant socio-economic impacts and although the outbreak revealed weaknesses in the health system, there is little evidence to suggest that this has been significantly improved since (Himelein et al. 2015; Painstil 2020, though see Kangbai 2020 for a counter argument). As a result, Sierra Leoneans were fearful of what the outbreak of COVID-19 could do to the country, particularly given the way it was being presented through the media to be ravaging other countries with much stronger health systems and economic structures. A middle age man from a rural community explained:

We are worried what will happen if this thing comes here, we remember Ebola and how bad it was. We are hearing what is happening in other countries like

China and we are worried what it would do to us here (23/03/20).

As the virus continued to spread more rapidly in countries outside of Africa, rumours began to emerge about Africa being the ideal inhabitable climate for COVID-19 to spread (Martinez-Alvarezt 2020). Sierra Leone recorded its first case of COVID-19 in Freetown on 31st March 2020 and the virus spread relatively slowly throughout the country, compared to other countries. However, despite this, Sierra Leone, like other African nations, took rapid action and put strict preventative measures in place very early on (cf. Capano et al. 2020), many of which mirrored the country's response to the outbreak of Ebola (see Leach 2020; Richards 2020). In Sierra Leone certain measures were put in place before the country had recorded its first case (cf. Dyer 2020), which resulted in people perceiving the government to be unnecessarily copying other countries' responses to the pandemic (cf. Dyer 2020; Engel 2020). For example, on 16th March 2020 Sierra Leone authorities restricted travellers from a number of countries with over 200 confirmed COVID-19 cases from entering the country as a method of preventing the spread of the virus into the country (WHO 2020a). This followed Ghana banning all travellers from a number 
of countries that had recorded high numbers of confirmed COVID-19 cases on 15th March 2020 (BBC News 2020). On 22nd March, the Sierra Leone government suspended all air traffic.

On March 25th, the Sierra Leone government declared a national State of Emergency (Garda World 2020a). This followed a number of other countries, including South Africa (15th March 2020) (Roelf 2020), Portugal (18th March 2020) (Reuters 2020) and Senegal (23rd March 2020) (Vanguard 2020) also declaring States of Emergencies. This is the third State of Emergency that Sierra Leone has experienced in six years. The frequency of these emergencies in recent years has made people suspicious of the government's motives as they are perceived to enhance the President's autonomy and control and reduce democratic systems (cf. Wilkinson and Leach 2014; Shepler 2016; Wilkinson and Fairhead 2017; Wilkinson et al. 2017; Leach 2020). On 27th March all borders in Sierra Leone were officially closed.

Following Sierra Leone recording the first COVID-19 case on 31st March, authorities implemented the first three-day total lockdown in the country on 5th April, to enable contact tracing. This followed other African countries such as Nigeria locking down Lagos for two weeks and South Africa ordering people to stay at home for three weeks (Medical Press 2020). On 8th May, the final day of the threeday total lockdown, protestors clashed with state police in Lunsar town in the Port Loko District of Sierra Leone over COVID-19 measures. On 11th April, a 14-day partial, inter-district lockdown, including a 9pm to 6am curfew, was introduced (McEwan 2020). The inter-district lockdown that was due to lapse on 25th April 2020 was then extended indefinitely on 24th April 2020 (Sierra Network Salone 2020). On 3rd May, Sierra Leone authorities implemented the second three-day total lockdown in the country, to enable more contact tracing (Garda World 2020b). On 6th May protestors clashed with state police again, in Tumbu in the Western Area Rural District over COVID-19 measures. On 1st June Sierra Leone authorities made mask wearing in public mandatory for all. This followed other countries including Vietnam (16th March 2020), Morocco (7th April 2020) and Cameroon (9th April)and a number of other African countries following the latter shortly after-making mask wearing mandatory (Al Jazeera News 2020).

It is worth noting that although the state-led COVID-19 measures were implemented early on and have been described as overly strict in relation to the way in which COVID-19 broke out in Sierra Leone, they have been enforced to varying degrees for different people and in different parts of the country. For example, the rules of the inter-district lockdown are that people are not allowed to move from one district to another unless they have a need to do so and then must obtain a pass that excuses them. However, there were rumours that people with the financial means and/or status have been able to bribe the police at check points and move around the country at their leisure. This is one example of how individuals experience the COVID-19 preventative measures differently and also how perception of others' experiences of the measures is different from their own. In addition to this, certain COVID-19 preventative measures such as mask wearing and washing hands were reported to be enforced much more strictly in Freetown than in other cities such as Makeni, this resulted in suspicions about what was going on in Freetown and enhanced the already-existing divide between Freetown and the provinces. It was 
beyond the scope of this study to explore how Sierra Leone's state-led measures were influenced by Ebola responses and/or other countries' COVID-19 responses; how COVID-19 measures were implemented in different places for different people in different ways in Sierra Leone; and the effects of this. However, these factors are considered as part of the context in which the individuals and communities in this study experienced, perceived and reacted to COVID-19 and its preventative measures in diverse ways.

Within the emerging Social Science literature on political and social COVID-19 pandemic responses, a number of state-led measures are outlined. These measures include social distancing, lockdowns, curfews and mandatory mask wearing (Dyer 2020; Eikenberry et al. 2020; Leach 2020). In this paper I show how individuals in Sierra Leone have understand and reacted to Sierra Leone's pandemic policiesnamely lockdowns, curfews and mandatory mask wearing. Through my analysis I show how sociocultural, economic and political contextual factors are central to explaining individual's understandings and various ways of reacting to state policies. In so doing, I identify contextual vulnerabilities and nuanced forms of adaptation and resistance that emerge in the face of a global pandemic.

\section{Literature Review}

There is an abundance of literature on state-led responses to COVID-19, and on how individuals are affected by responses in different ways and, to some extent, how people react to responses. Despite this, a one-size-fits-all approach to preventing the spread of the virus continues to dominate and African vulnerability to disease outbreak is still largely homogenised within the COVID-19 literature. In this paper, I challenge this approach by showing the nuanced ways in which individuals experience and respond to state-led COVID-19 preventative measures in Sierra Leone.

\section{State-Led Responses to COVID-19}

Within the rapidly increasing body of literature concerned with the COVID-19 pandemic, studies focus on numerous aspects of the outbreak. These include medical (see for example Anderson et al. 2020; Rothan and Byrareddy 2020), economic (see, for example, Guerrieri et al. 2020; Nicola et al. 2010), social (see for example Holmes et al. 2020; WHO 2020b) and political (see for example Grossman et al. 2020; Painter and Qiu 2020) examinations, as well as how state-led preventative measures have been implemented and experienced by different people, in different countries in different ways (see for example Capano et al. 2020; Leach 2020).

It is worth noting here, that there is much debate concerning the definition of 'state' (Jessop 2007, 2016). In this paper, 'state' is used to refer to a collective number of institutions such as the political executive, legislature, judiciary, army, police and public administration that perform a number of functions including decision-making and exerting power and control over the general population (Jessop 2007). 'State-led responses' are used to refer to measures that have been selected 
and implemented by the national government in response to the COVID-19 pandemic. 'State-led measures' are used to describe top-down initiatives conceived by national governments that are then implemented by local administrative branches through bureaucratic systems (see for example Sikor and Müller 2009). Top-down preventative health measures, such as those implemented during the Ebola outbreak in West Africa, have been shown to be inappropriate, and in some cases damaging to local contexts (see Fairhead 2016; Abramowitz 2017; Wilkinson and Fairhead 2017; Wilkinson et al. 2017; Dyer 2020; Engel 2020; Leach 2020; Richards 2020).

A number of scholars (see for example, Dahab et al. 2020; Madhi et al. 2020; de Oliveira Andrade 2020) note how similar state-led COVID-19 preventative measures have been implemented in both so-called developing and developed nations that followed WHO COVID-19 recommended guidelines (Saire and Porford-Quainoo 2020). Saire and Porford-Quainoo (2020) highlight the dangers of applying a onesize-fits-all approach in addressing a global pandemic (see also Dahab et al. 2020; Madhi et al. 2020; de Oliveira Andrade 2020).

Capano et al. (2020) offer a more nuanced analysis of how similar preventative measures have been implemented in different countries, in different ways, at different times. They argue that the way in which countries have responded to the outbreak of COVID-19 is influenced by a country's previous experience of disease outbreak and state capacity. For example, some Asian countries have experience of other disease outbreaks and a realistic confidence in the capability of their public health and financial systems to handle health epidemics. As a result, they responded to the COVID-19 pandemic with effective measures, implemented slowly and steadily from a relatively early stage (Capano et al. 2020). Capano et al. (2020) argue that other countries in Europe and North America were confident in their capacity to handle the outbreak but lacked the competencies. These countries had weaker responses that were implemented slowly and later on. Countries that were unprepared and lacked recent relevant experience such as Italy and some countries in Latin America were late and slow to initially respond and then initiated a strong panic response (Capano et al. 2020). African governments who have experience of recent health epidemics and acknowledge the weaknesses in their health systemslike Sierra Leone-implemented strict measures quickly (Capano et al. 2020).

The success in responding to a health epidemic is argued to be related to, at least in part, state capacity and legitimacy (see Boone and Batsell 2001; Hartley and Jarvis 2020; Woo 2020). For example, Boone and Batsell (2001) show how different countries have responded to the AIDS epidemic to varying levels of success based on a state's willingness and capacity to do so. Woo (2020) explains how in Singapore the state's fiscal, operational and political capacities have kept the COVID-19 mortality rate low for much of the population. However, deficiencies in the state's analytical capacity in terms of assessing risks for certain populations have resulted in high rates of COVID-19 in foreign worker living quarters (Woo 2020). Hartley and Jarvis (2020) argue that in countries where the population lacks trust in the government and the state is therefore lacking in legitimacy are at a disadvantage in responding to crisis. In these so-called low-trust states, such as Hong Kong, local community capacity is shown to be essential in the successful management of crisis. This study contributes to debates on political legitimacy, state and community 
capacity, by exploring these issues from the perspectives of citizens rather than the perspective of the state and political elites. In so doing, I show how state-society relations influence how individuals react to state policies and shape the outcome of these.

\section{The Individual Experience}

Anderson et al. (2020) and Hartley and Jarvis (2020) argue that the ways in which individuals respond to government advice and state policies are as important as the measures themselves in terms of managing a health epidemic. The way individuals perceive the capabilities of the state and experience state-led responses is therefore critical to understanding the outcomes of epidemics. An abundance of studies explore the ways in which individuals experience epidemics and their related stateled measures in unique ways.

For example, women and men are found to experience health epidemics in different ways (see, for example, Strong and Schwartz 2016; Smith 2019; Gyasi and Anderson 2020). Studies have shown that women are often more vulnerable to communicable diseases due in part to the caregiving roles they play in society (for example, Strong and Schwartz 2016; Smith 2019; Gyasi and Anderson 2020). Women are found to be more vulnerable to contracting certain contagious illnesses through their role of taking care of the sick through which they often have to come into close contact with people thus substantially increasing their risk to exposure and infection (Smith 2019).

Forcibly displaced people have also been found to be particularly vulnerable to communicable disease outbreaks such as COVID-19 (see Dahab et al. 2020). This is due to a number of factors including overcrowding in displaced people's camps. People living in informal (slum) settlements have also been found to be particularly vulnerable to health epidemics and the socio-economic effects of these (Ahmed et al. 2020). There are a number of influencing factors here, including many people being involved in daily wage work, that cannot be done from home, often being halted by disease outbreaks resulting in a loss of income. Accessing healthcare is also an issue for slum residents during communicable health outbreaks due to the risks for health practitioners entering the community and the poor road networks preventing emergency vehicles to transport people out of the slum areas to a healthcare facility (Ahmed et al. 2020; de Oliveira Andrade 2010).

People in low-income countries in Latin America and Africa have been found to be particularly vulnerable to health emergencies and the socio-economic effects associated with them. Africans are said to be particularly vulnerable to health emergencies due to factors such as poor health systems, poverty and cultural norms (Kieny et al. 2014; O'Hare 2015; Nielsen et al. 2014; Engel 2020; Gilbert et al. 2020; Ozili 2020). For example, the 2014-2015 Ebola outbreak showed how countries in West Africa are vulnerable to disease outbreaks and the negative effects associated with these, in part due to the weak health systems of these countries (O'Hare 2015). 
People in low-income countries are also argued to be particularly vulnerable to a number of state-led preventative measures, such as lockdowns, and the socio-economic effects of these (see Abramowitz 2017; Bargain and Aminjonov 2020; Engel 2020; Martinez-Alvarezt 2020). One reason for this is that a large proportion of the population are often dependent on daily hands-on labour and need to leave their house every day to survive (Bargain and Aminjonov 2020; Engel 2020; MackworthYoung et al. 2020; Martinez-Alvarezt 2020; Ozili 2020).

People in African countries have been shown to be particularly vulnerable to human rights abuses during the COVID-19 period (Amadasun 2020). For example, law enforcers have been found to use excessive force when implementing COVID-19 preventative measures in many African countries such as Nigeria, Zimbabwe, Kenya and South Africa (Amadasun 2020). Elderly people in African countries have been found to be particularly vulnerable to certain preventative measures such as lockdowns and social distancing. This is because such measures separate elderly people from their loved ones, restricting their access to essential supplies and causing a loss of freedom and uncertainty of disease status (Gyasi and Anderson 2020). The ways in which Africans are presented as vulnerable to numerous negative aspects of disease outbreaks, however, largely hide the nuanced ways in which individuals enact their agency in response to COVID-19 and its effects.

There is a dominant narrative running through the literature concerned with the specific effects that COVID-19 and its measures are having on individuals: that measures should be contextually tailored, take local behavioural norms into consideration and be community-led (Leach 2020; Mackworth-Young et al. 2020; Richards 2020). Despite this recommendation, top-down strategies continue to dominate (see Mackworth-Young et al. 2020).

\section{Reactions to COVID-19}

While much of the literature discusses the delivery of pandemic policies and people's vulnerabilities to health epidemics, some focuses on individual and community capacity to respond to these and their state-led measures. For example, some scholars argue that 'the poor' are seen to be less compliant to lockdown measures due to having to leave the house for paid employment as a means of survival (see Bargain and Aminjonov 2020; Mackworth-Young et al. 2020).

There is also evidence to show that people living in slum communities adapt to the problem of accessing healthcare during a health epidemic in different ways. For example, people in slum communities in Bangladesh, Kenya, Nigeria and Pakistan have created ways of using mobile phones to access healthcare during COVID-19 outbreaks, whereas in Brazil, the G10 Favelas project-made up of community leaders from a number of slum communities - hired a private healthcare system to work in Paraisópolis_-Brazil's largest slum (de Oliveira Andrade 2020).

In addition, people have been shown to violently resist state-led preventative measures during health epidemics, such as the Ebola outbreak in West Africa (see, for example, Fairhead 2016; Wilkinson and Fairhead 2017; Wilkinson et al. 2017; Leach 2020). Certain state-led measures such as nationally implemented and 
enforced lockdowns are, it is argued, seen as forms of structural violence, bound up in colonial systems of local exploitation for national and international gain (Wilkinson and Leach 2014; Wilkinson et al. 2017; Leach 2020). Related to this, is the distrust many communities felt towards the state and international non-government organisations (INGOs) during the Ebola epidemic, in response to allegations of them spreading the virus intentionally, and in questioning where relief money was actually going (Wilkinson and Leach 2014; Shepler 2016; Wilkinson and Fairhead 2017; Wilkinson et al. 2017; Leach 2020).

In both Sierra Leone and Guinea, people actively resisted Ebola measures. A study in Sierra Leone during the 2014-2015 Ebola outbreak by Maxmen (2015, cited in Leach 2020) showed how people living in Freetown's informal settlements, the majority of whom have little money and need to go out every day to find the means-water, food and money - to survive, took to the streets to protest the threeday total lockdown and its effects including a lack of access to food. In Guinea, it is argued, communities violently resisted state policies by attacking and killing people involved in the international response to Ebola due to suspicion and lack of trust (Fairhead 2016; Wilkinson and Fairhead 2017; Wilkinson et al. 2017).

\section{Methodology}

As a result of anthropologists often lacking the ability to conduct research during times of crises, they sometimes depend on previous research conclusions, presenting vulnerabilities that exist during 'normal times' as heightened during crises. For example, women and pregnant women have, in particular, been described as homogenous groups of passive victims of health emergencies (Abramowitz 2017). As I was (and continue to) living in Sierra Leone during the entirety of the COVID-19 outbreak and was able to conduct research during this time, I am able to offer unique insights into the effects of the crisis. Findings are based on ethnographic data collected in Makeni city and three rural communities in Bombali District, north Sierra Leone, to identify and understand the nuanced individual experiences and reactions to the outbreak of COVID-19 and its preventative measures. Data were collected through questionnaires, interviews, participant observation and reviewing secondary data-press releases and media reports-during the outbreak of COVID-19 in the country, from 23rd March to 6th May 2020. It is worth noting that during this time, there were very few cases in Bombali District. The first case in the district was confirmed on 26th April 2020 and by 6th May, the district had less than 10 confirmed cases. The three rural communities had zero confirmed cases for the entirety of the study.

Questionnaires were conducted with a total of 57 people. This includes 39 people in three rural communities representing different demographics of people. The majority of individuals living in the three villages are from the Limba ethnic group, with the exception of a few Temne people. A translator proficient in both languages helped conduct all the questionnaires and interviews in the three villages. All village participants described themselves as being involved in some type of agricultural activity, whether part-time or full-time, making differentiating individuals by 
profession inappropriate. Individuals were thus defined by different demographics along age and gender lines as well as different leadership positions in the villages. Those in positions of leadership were considered to have a broad understanding of how COVID-19 was affecting their community as a whole. In each of the villages, a young woman, a middle age woman, an old woman, a young man, a middle age man, an old man, a teacher, the youth leader, the Mammy Queen (female leader) and the male Village Chief were surveyed to examine diverse experiences and opinions of COVID-19 and its preventative measures. In addition, individuals engaged in popular professions in Makeni town, which were particularly affected by the COVID-19 measures, were also surveyed. This included 10 market sellers, selling different produce, 2 tailors, 2 public transport motorbike riders and 2 traders from outside of the main market. Follow-up interviews were then held with people that had expressed noteworthy experiences of COVID-19 and the related measures.

The research was conducted as part of the University of Makeni's COVID-19 outreach programme. The study was designed, in part, to understand collective and individual people's experiences and perceptions of COVID-19 and its preventative measures in order to better tailor response efforts. During this unusual time, ethical considerations in terms of health and safety for both the participants, interpreter and researcher, were of paramount concern. For this reason, a convenience sampling method was used in addition to the representative method-that is outlined above. For example, in addition to selecting participants who represented the above identified demographics, participants were also selected on the basis of their availability and willingness to be involved in the research during the outbreak of the virus (cf. Lohr 2010; Górny and Napierala 2016).

The University of Makeni's ethical guidelines were followed throughout the research. Before each research method was conducted with each potential participant, consent and ethics were discussed. Each participant was informed about the aim of the research—understanding people's experiences of COVID-19-and the risks of participating in the research, specifically related to the pandemic context. For example, the risk of talking to someone whose health status you do not know during a communicable disease outbreak. Individuals were asked to state whether they understood the risks and whether they consented to taking part in the study. All face-to-face methods were conducted following Sierra Leone's national social distancing rules that were in place at the time of the research, including the recommended wearing face masks in public places. Participants that did not have a face mask were provided with one, but it was their choice whether to take it and/or wear it during the research process.

Secondary data including press releases and media reports were also reviewed to understand the state-led measures and the way in which they were being implemented and understood at the local level. These data were obtained from a range of sources, including collecting official government statements about the implementation of COVID-19 measures in Sierra Leone. In addition to this, participants provided and therefore selected press releases and media reports that were influential to the way they perceived COVID-19 and Sierra Leonean state-led measures. The majority of these sources were obtained by participants and the researcher from the radio, the internet or social media groups (cf. Mackworth-Young et al. 2020). Social 
media forums such as WhatsApp are one of the most popular ways of sharing information in Sierra Leone, particularly in urban areas. WhatsApp is used to share both official information-including government statements-and unofficial information-including false government statements and reports of people's opinions and behaviour-concerning issues - in Sierra Leone. Press releases and media reports are therefore commonly shared on most WhatsApp groups. These press releases and media reports along with individual perceptions of these and experiences of and reactions to COVID-19 and the state-led preventative measures were analysed using a thematic coding approach. The main findings that emerged from the data were that individuals from different demographic groups understood and experienced Sierra Leone's state-led measures in diverse and nuanced ways, causing communities to react in a diversity of ways, including adapting, not complying and passively and actively resisting the state-led COVID-19 preventative measures.

\section{Discussion}

\section{Experiences of COVID-19 in Sierra Leone}

The findings of this study find older (approximately 50 years and above) women and men in rural communities to be particularly vulnerable to the negative effects of the inter-district lockdown that was introduced in Sierra Leone on 11th April 2020 (cf. Gyasi and Anderson 2020). As part of this measure, people were not allowed to move from one district to another. This had a particular effect on older people in rural villages in Bombali District in the north of the country as many are reliant on grown-up children that live in Freetown, located in the Western Urban district of the country, or other cities in other districts visiting them to provide both social and financial support.

The inter-district lockdown resulted in people not being able to visit older relatives to support them; this was particularly difficult for older people in rural areas. People in urban areas can more easily receive financial support through mobilemoney that can be sent from anywhere in the country to someone's mobile number and picked up from a local mobile-money agent, than those in rural areas. This is because not all villages have mobile-money agents and it is not too common for people, particularly older women, to have mobile phones in rural communities. Older people in rural communities are therefore vulnerable to increased poverty and feelings of loneliness as a result of lockdown measures (cf. Gyasi and Anderson 2020). This highlights the different ways in which different individuals as defined along age, gender and urban/rural divide lines experience the inter-district lockdown in Sierra Leone. This also highlights how state-led restrictions on people's movements are a particular issue for older people in isolated locations in countries where care and support are predominantly offered by physical contact with family members.

The aforementioned negative ways in which older people in rural communities experienced Sierra Leone's COVID-19 inter-district lockdown measures demonstrate deficiencies in the state's capabilities in analysing and responding to the needs of this sector of its population (cf. Woo 2020). In low-trust states in which state 
policies to the pandemic are seen to be inefficient and/or inappropriate, community capabilities play a significant role in managing the crisis and its effects (cf. Hartley and Jarvis 2020).

In this paper, individuals' reactions to the effects of state-led COVID-19 policies are analysed using adaptive capacity, compliance and passive and active resistance theories. The findings of which show how individuals' capabilities have influenced their ability to adapt, comply with and resist state-led COVID-19 measures. In so doing, local capabilities are shown to have shaped Sierra Leone's COVID-19 response and the socio-economic effects of this.

\section{Adaptation}

Findings show that women with social and financial capital and drawing on their experiences of Ebola adapt to the three-day lockdowns by offering loans to other women, who are responsible for feeding their family members but cannot afford to buy enough food for the three days (cf. Chaudhury et al. 2017). The women offering loans charge interest for this service and therefore financially benefit from the threeday total lockdowns.

Participants explained that some families in the three villages and in Makeni could not afford to buy enough food for their families for a three-day total lockdown. The social burden of this is more often carried by a woman as it is seen as a woman's responsibility to feed her family (Jones 2020). Thus, women who are financially secure have responded in both rural and urban communities by offering loans to those women in both the form of cash before the commencement of the lockdown and in the form of food during the lockdown. These women were able to financially benefit from the lockdown by charging interest. This is demonstrated in the following quotes:

Some of the women in this village are poor and cannot afford to go to the market and buy enough food for the three days. Due to this I gave them food on the third day when their food had run out. They will pay me for this when they can with a bit extra for me (middle age woman from rural community, 13/04/2020).

There are some women in my community here in Makeni that cannot afford to buy enough food because they were not given warning. I have some money from my business so I did lend them some to buy enough food before the lockdown started. They will pay me back with interest later (middle age woman, Makeni, 29/04/2020).

The above quotes also show how women with social capital were able to borrow from women with financial capital to more comfortably survive the lockdown. The second quote also highlights the issue of needing time to prepare for total lockdowns, particularly for people that do not have savings to fall back on. For the two three-day lockdowns that were implemented in Sierra Leone, communities were given only three days warning (see Garda World 2020a; Medical Press 2020). This was not enough time for many to save enough money to be able to 
adequately prepare, including for women to be able to get enough money for food to be able to feed their families.

Some women, particularly in the rural areas, said that they experienced long lockdowns during Ebola, during which time they struggled to provide enough food for their families. From this experience, they drew on those that could help those without financial capacity. This demonstrates how women are not only responsible for their own families but also the welfare of the other families in their communities. It also highlights the communal nature of local people's response to the COVID-19 pandemic and its effects in an Africa context such as Sierra Leone (cf. Wilkinson et al. 2017).

In addition to some women in both the rural and urban areas adapting by providing loans for other women to feed their families during the three-day total lockdowns, findings also show how tailors adapted and financially benefited from mandatory mask wearing by producing cloth masks. When mask wearing that had already been made mandatory in other Sub-Saharan African countries including Ghana and Kenya, for example, was strongly encouraged in public places in Sierra Leone, a number of tailors reported either taking the initiative to start making and selling cloth masks to sell to people in Makeni and/or others commissioning them to make these masks to give out to people as part of individual's and local, national and international COVID-19 outreach programmes.

It is worth noting here that mandatory mask wearing was not introduced in Sierra Leone until 1st June. However, people (correctly) predicted that mask wearing would at some point be made mandatory in the country. People explained they were able to predict this because Sierra Leone's COVID-19 stateled preventative measures were following those being implemented in other countries. In this case, Sierra Leoneans observed that mask wearing was being made mandatory in other African countries-including South Africa, Nigeria, Ghana, Kenya-as well as non-African countries-such as China, Taiwan, Hong Kong (see Al Jazeera News 2020)_and saw the need to prepare for the same measure.

One tailor explained that she saw on social media that other African countries were making mask wearing mandatory and thought this might become compulsory in Sierra Leone. In addition to this, some people had already started wearing masks in the country, some of her customers work for international NGOs and were being advised to wear masks and had asked her if she could make them. As a result of these factors, she decided to start making them both for individuals and then people working in the COVID-19 response started ordering large quantities to distribute to people. It was estimated that tailors making and selling cloth masks increased their daily profit by around 500\% in April.

These two examples-local women offering loans within their communities and tailors making and selling face masks-demonstrate how certain individuals have been able to financially benefit from the COVID-19 outbreak and the government's responses in Sierra Leone at the local level. 


\section{Non-compliance}

In contrast to some individuals adapting to the state-led COVID-19 measures, others have been unable to comply with certain measures. Wilkinson and Fairhead (2017) make the distinction between resistance and non-compliance, explaining that the latter is often caused by an individual's lack of social and/or economic capital to be able to do something, rather than intentionally refusing to comply. My findings show that during the two three-day total lockdowns during the outbreak of COVID19, women in particular in Makeni town, an urban area, were found to leave their compounds to fetch water for their families. Women explained that it is women and children that have to break the curfew because it is seen as a woman's responsibility - and children helping them-to fetch water in order to fulfil many of their domestic roles, such as cooking, cleaning and laundering clothes that require water. It is common for this water source to be outside of the person's compound in Sierra Leone, thus some women were forced to break the lockdown to fetch water for their family's needs (cf. Wilkinson and Fairhead 2017). Women that broke the total lockdown measures to fetch water risked physical punishment from state police. There were a number of reports circulating on social media after both of the three-day total lockdowns that police were using violence to enforce the lockdown measures, including against women who were out fetching water.

In contrast, people in the three rural villages do not tend to live in compounds and interpret total lockdowns differently to those in urban areas, as they think of the whole of the community being locked down together rather than by house (cf. Hoffman 2016). Anthropologist, Catherine Bolten, explains that being ordered to 'stay at home' during a lockdown is understood by individuals in different ways in different contexts. She offers the following examples as places that individuals perceive as 'home' in Sierra Leone: rural ancestral villages, multiple urban residences, outlying farms and labour encampments (cited in Hoffman 2016). Collecting water from the community water well or borehole in the village was therefore not perceived as breaking the lockdown as they were moving within their village home. In addition to this, there were no police in the three rural communities enforcing lockdown measures, such as staying in their houses. This highlights how context informs the ways in which individuals and communities perceive, experience and react to state-led COVID-19 measures in different ways and also regard their level of compliance.

\section{Passive Resistance}

In addition to people not being able to conform to certain state-led COVID-19 preventative measures, some individuals also passively resisted them. Passive resistance is defined here as people intentionally resisting certain state-led, top-down measures. However, in contrast to active resistance, passive resistance is not aiming to change the measure but instead maintain and/or enhance their standard of living that is being threatened by the exploitative measure that is being enforced by state elites, related to perceived international capitalist initiatives (cf. Scott 1985). For example, okada (motorbike) riders as well as other participants explained that they 
believed that the three-day total lockdowns and other state-led COVID-19 measures were unnecessary and only being implemented by the government to attract international financial support for their efforts. Public transport drivers, including motor car and okada, have passively resisted the district lockdown, including the $9 \mathrm{pm}$ curfew, as it reduces their business hours and profit (cf. Scott 1985).

Some public transport motor cars continued to pass from one district to another and were reported to be bribing the police at the check points to let them pass. In part as a result of this, the cost of travelling by public transport increased during the inter-district lockdown. Okada riders also continued to travel after 9 pm, explaining that this is one of their busiest times and that there was a need for them to take people home. Reports were made of okada riders charging more for people to travel after $9 \mathrm{pm}$, because of the risk of being arrested by the police, therefore increasing their profits as a result of the curfew. Not everyone was able to afford these increases in public transport costs. This therefore exemplifies how individuals with different financial capital experience COVID-19 measures and their effects in different ways.

\section{Active Resistance}

In addition to some people adapting, some people not being able to conform and some people passively resisting, others have actively resisted the COVID-19 preventative measures implemented in Sierra Leone. For example, some male youths have actively resisted the three-day total lockdowns by storming town centres and burning buildings including hospitals and police stations in demonstration of their discontent with the lockdown measures (cf. Harvey 2003). After both of the threeday total lockdowns that were enforced during the outbreak of COVID-19 in Sierra Leone, reports, photographs and videos circulated on social media platforms showing that large numbers of male youths had taken to the streets on the last day of the lockdowns to express their discontent and frustration with being locked down and that these protests were met with physical force from the police. There was a consensus among the participants in this study that they understood why youths were protesting the three-day lockdowns in this way, as demonstrated in the following quote by a woman selling fish in the Makeni central market:

What else are they to do? No one is listening to us. Three days is too long, we do not have water, we do not have food, so how are we to survive like this?

This government is not listening to us (29/04/2020).

This quote not only illustrates discontent with the three-day lockdowns, but also touches upon the political tensions that underpin the ways in which people in the Bombali district - the majority of whom are supporters of the All People's Congress (APC) party-perceived the COVID-19 preventative measures that were implemented by the ruling Sierra Leone People's Party (SLPP) government during the pandemic. The belief by many participants was that the ways that the outbreak of COVID-19 in Sierra Leone was reported and the preventative measures that were introduced were for the purpose of attracting international funding. Similar to Ebola, people were sceptical about how this aid would be used and therefore resistant to 
some of the COVID-19 preventative measures that they felt were socio-economically inappropriate and unnecessary given the low level of the outbreak when they were being implemented (cf. Shepler 2016; Leach 2020). By highlighting the political aspect of citizens' everyday reactions to state policies in the COVID-19 context, this paper contributes to the academic debate on political dimensions of pandemic responses.

\section{Conclusion}

In contrast to assumptions in the existing literature that Africans and African nations are homogenous victims of health emergencies and their preventative measures (Abramowitz 2017; Engel 2020; Martinez-Alvarezt 2020), my findings show how individuals experience COVID-19 and its measures in different and nuanced ways. For example, older women and men in rural areas were found to be particularly vulnerable to the inter-district lockdown, while other individuals were found to adapt, not comply and passively and actively resist state policies.

In this paper, I highlight a number of factors that influence the ways in which individuals experience, perceive and react to COVID-19 and its measures in Sierra Leone. These factors include age, gender, profession, political affiliation, life experiences including of previous health emergencies, communal way of living and the rural/urban divide that exists in Sierra Leone. Findings emphasise the heterogeneity of Sierra Leonean's experiences and responses to COVID-19 measures. In addition to this, the findings show how individual capabilities shape the local socio-economic effects of the pandemic. This paper thus contributes to the academic debate on state-society relations in the pandemic response.

However, this paper is by no means a comprehensive study of how all people in Sierra Leone have experienced and responded to COVID-19 and its effects, in part due to conducting the study during the pandemic and needing to follow certain health and safety precautions, including following the preventative measures that were in place at the time. More research is therefore needed into how individuals in diverse demographic categories experience, perceive and react to COVID-19 and its effects in other parts of Sierra Leone as well as in other countries. However, from the findings of this study, it is clear that it is critical to consider the diversity of needs and priorities in any given context not only in different countries but also within a country and particularly African countries when responding to a global pandemic.

\section{Compliance with Ethical Standards}

Conflict of interest The corresponding author states that there is no conflict of interest.

\section{References}

Abramowitz, S. 2017. Epidemics (Especially Ebola). Annual Review of Anthropology 46 (1):421-445. 
Agyeman, A.A., A. Laar, and R. Ofori-Asenso. 2020. Will COVID-19 be a litmus test for post-Ebola subSaharan Africa? Journal of Medical Virology 92 (9): 1373-1375.

Ahmed, S.A.K.S., M. Ajisola, K. Azeem, et al. 2020. Impact of the societal response to COVID-19 on access to healthcare for non-COVID-19 health issues in slum communities of Bangladesh, Kenya, Nigeria and Pakistan: Results of pre-COVID and COVID-19 lockdown stakeholder engagements. BMJ Global Health 5: 1-17.

Al Jazeera News. 2020. Which countries have made wearing face masks compulsory? 3 June. https:// www.aljazeera.com/news/2020/04/countries-wearing-face-masks-compulsory-200423094510867 .html. Accessed 5 June 2020.

Amadasun, S. 2020. COVID-19 palaver: Ending rights violations of vulnerable groups in Africa. World Development 134: 1-2.

Anderson, R., H. Heesterbeek, D. Klinkenberg, and T.D. Hollingsworth. 2020. How will country-based mitigation measures influence the course of the COVID-19 epidemic? The Lancet 395: 931-934.

Bargain, O., and U. Aminjonov. 2020. Poverty and COVID-19 in developing countries. Bordeaux: Bordeaux Economics Working Paper, BxWP2020-08.

BBC News. 2020 Coronavirus-Virus: Ghana schools closed, religious, sports activities chop ban to fight Covid-19 disease. 16 March. https://www.bbc.com/pidgin/tori-51904164. Accessed 5 June 2020.

Boone, C., and J. Batsell. 2001. Politics and AIDS in Africa: Research agendas in political science and international relations. Africa Today 48 (2): 3-33.

Capano, G., M. Howlett, D.S.L. Jarvis, M. Ramesh, and N. Goyal. 2020. Mobilizing policy (in)capacity to fight COVID-19: Understanding variations in state responses. Policy and Society 39 (3): 285-308.

Chaudhury, A., T. Thornton, A. Helfgott, M. Vantressa, and C. Sova. 2017. Ties that bind: Local networks, communities and adaptive capacity in rural Ghana. Journal of Rural Studies 53: 214-228.

Dahab, M., K. van Zandvoort, S. Flasch, A. Warsame, R. Ratnayake, C. Favas, P.B. Spiegel, R.J. Waldman, and F. Checchi. 2020. COVID-19 control in low-income settings and displaced populations: What can realistically be done? Conflict and Health 14: 54.

de Oliveira Andrade, R. 2020. The Brazilian slums hiring their own doctors to fight COVID-19. BMJ 369: 1571.

Dyer, O. 2020. Covid-19: Africa records over 10000 as lockdowns take hold. BMJ 369: m1439.

Eikenberry, S.E., M. Mancuso, E. Iboi, T. Phan, K. Eikenberry, Y. Kuang, E. Kostelich, and A.B. Gumel. 2020. To mask or not to mask: Modeling the potential for face mask use by the general public to curtail the COVID-19 pandemic. Infectious Disease Modelling 5: 293-308.

Engel, U. 2020. Public health policies beyond the state: A socio-spatial analysis of early responses to Covid-19 in Africa, 2020. https://d1wqtxts1xzle7.cloudfront.net/63072696/_Engel_2020_Respo nses_to_Covid-19_in_Africa20200424-59096-9aae5c.pdf? Accessed 17 June 2020.

Fairhead, J. 2016. Understanding social resistance to the Ebola response in the forest region of the Republic of Guinea: An anthropological perspective. African Studies Review 59 (3): 7-31.

Górny, A., and J. Napierala. 2016. Comparing the effectiveness of respondent-driven sampling and quota sampling in migration research. International Journal of Social research Methodology 19 (6): 645-661.

Garda World. 2020a. Sierra Leone: National state of emergency declared March 25/update 3. 26 March. https://www.garda.com/crisis24/news-alerts/326706/sierra-leone-national-state-of-emergency-decla red-march-25-update-3. Accessed 15 May 2020.

Garda World. 2020b. Sierra Leone: Three-day lockdown to be introduced from May 3/update 8. 2 May. https://www.garda.com/crisis24/news-alerts/338251/sierra-leone-three-day-lockdown-to-be-intro duced-from-may-3-update-8. Accessed 15 May 2020.

Gilbert, M., G. Pullano, F. Ponotti, E. Valddano, C. Poletto, P. Boëlle, E. D’Ortenzio, Y. Yazdanpanah, S.P. Eholie, M. Altman, M.U.G. Kramer, and V. Colizza. 2020. Preparedness and vulnerability of African countries against importations of COVID-19: A modelling study. Lancet 395: 871-877.

Grossman, G., S. Kim, J. Rexer, and H. Thirumurthy. 2020. Political partisanship influences behavioral responses to governors' recommendations for COVID-19 Prevention in the United States. SSRN. https://papers.ssrn.com/sol3/papers.cfm?abstract_id=3578695. Accessed 22 June 2020.

Guerrieri, V., Lorenzoni, G., Straub, L. and Werning, I. (2020) Macroeconomic implications of COVID19: Can negative supply shocks cause demand shortages? National Bureau of Economic Research, Working Paper 26918.

Gyasi, R.M., and E.A. Anderson. 2020. Whither are we bound? Rethinking the gendered frailty during COVID-19 pandemic. Public Health in Practice 1: 1-2. 
Hartley, K., and D.S.L. Jarvis. 2020. Policymaking in a low-trust state: Legitimacy, state capacity, and response to COVID-19 in Hong Kong. Policy and Society 39 (3): 403-423.

Harvey, D. 2003. The new imperialism. Oxford: Oxford University Press.

Himelein, K., M. Testaverde, A. Turay, and S. Turay. 2015. The socio-economic impacts of Ebola in Sierra Leone. World Bank and Statistics Sierra Leone.

Hoffman, D. 2016. A crouching village: Ebola and the empty gestures of quarantine in Monrovia. City \& Society 28(2): 246-264

Holmes, E.A., R.C. O’Connor, V.H. Perry, I. Tracey, S. Wessely, L. Arseneault, et al. 2020. Multidisciplinary research priorities for the COVID-19 pandemic: A call for action for mental health science. The Lancet 7 (6): 547-560.

Jessop, B. 2007. State power: A strategic-relational approach. Cambridge: Polity Press.

Jessop, B. 2016. The state (keyconcepts): Past, present, future. Cambridge: Polity Press.

Jones, J. 2020. A study of women's agency and mining-induced displacement and resettlement. PhD Thesis, University of East Anglia.

Kangbai, J. B. (2020) Sierra Leone is using lessons from Ebola to prepare for coronavirus. The Conversation. https://theconversation.com/sierra-leone-is-using-lessons-from-ebola-to-prepare-for-coron avirus-132443. Accessed 10 June 2020.

Kieny, M., D.B. Ebans, G. Schmets, and S. Kadandale. 2014. Health system resilience: Reflections on the Ebola crises in western Africa. World Health Organization 92 (12): 850.

Leach, M. 2020. Echoes of Ebola: Social and political warnings for the COVID-19 response in African settings. http://somatosphere.net/forumpost/echoesof-ebola/. Accessed 20 June 2020.

Lohr, A. 2010. Sampling design and analysis. Boston, MA: Cengage Learning.

Mackworth-Young, C. R. S., Chingon, R., Mavodza, C. McHugh, G., Tembo, M., Dziva, C. C., Weiss, H. A., Rusakaniko, S. Ruzario, S., S. Bernays, and R. A. Ferrand. 2020. 'Here, we cannot practice what is preached': Early qualitative learning from community perspectives on Zimbabwe's response to COVID-19. Bulletin of the World Health Organization. ISSN 0042-9686.

Madhi, S.A., G.E. Gray, N. Ismail, A. Izu, M. Mandelson, N. Cassim, W. Stevens, and F. Venter. 2020. COVID-19 lockdowns in low- and middle-income countries: Success against COVID-19 at the price of greater costs. SAMJ 11 (8): 724-726.

Martinez-Alvarezt, M. 2020. COVID-19 pandemic in west Africa. The Lancet 8: 631-632.

McEwan, F. B. (2020) A 14-day inter-district lock down has been issued in Sierra Leone. SwitSalone, 9 April. https://www.switsalone.com/36241_a-14-day-inter-district-lock-down-has-been-issued-insierra-leone/. Accessed 30 Apr 2020.

Medical Press. 2020. Sierra Leone announces three-day lockdown against coronavirus. 1 April. https:// medicalxpress.com/news/2020-04-sierra-leone-three-day-lockdown-coronavirus.html. Accessed 7 Apr 2020.

Nicola, M., Z. Alsafi, C. Sohrabi, A. Kerwan, A. Al-Jabir, C. Iosifis, M. Agha, and R. Agha. 2010. The socio-economic implications of the coronavirus pandemic (covid-19): A review. International Journal of Surgery 78: 185-193.

Nielsen, C.F., S. Kidd, A.R.M. Sillah, E. Davis, J. Mermin, and P.H. Kilmarx. 2014. (2016) Improving Burial Practices And cemetery management during an Ebola virus epidemic-Sierra Leone. Morbidity and Mortality Weekly Report 64 (1): 20-27.

O'Hare, B. 2015. Weak health systems and Ebola. The Lancet 3: 71-72.

Ozili, P. 2020. COVID-19 in Africa: Socio-economic impact, policy response and opportunities. International Journal of Sociology and Social Policy. https://doi.org/10.1108/IJSSP-05-2020-0171.

Painstil, E. 2020. Covid-19 threatens health systems in sub-Saharan Africa: The eye of the crocodile. The Journal of Clinical Investigation 130 (6): 2741-2744.

Painter, M., and T. Qiu. 2020. Political beliefs affect compliance with COVID-19 social distancing orders. CEPR Policy Portal.

Reuters. 2020. Portugal prepares to extend state of emergency as deaths rise to 187. 1 April. https://www. reuters.com/article/us-health-coronavirus-portugal/portugal-prepares-to-extend-state-of-emergencyas-deaths-rise-to-187-idUSKBN21J5P7. Accessed 30 Apr 2020.

Richards, P. 2020a. Self-quarantine for infectious diseases needs flexible public authority. https://blogs .1se.ac.uk/africaatlse/2020/02/10/self-quarantine-infectious-diseases-ebola-coronavirus-public-autho rity/. Accessed 10 June 2020.

Roelf, W. 2020. UPDATE 1-South Africa's Ramaphosa declares state of disaster over COVID-19. Reuters. 15 March. https://www.reuters.com/article/health-coronavirus-safrica-idUSL8N2B8163. Accessed 30 Apr 2020 
Rothan, H.S., and S. Byrareddy. 2020. The epidemiology and pathogenesis of coronavirus (COVID-19) outbreak. Journal of Autoimmunity 109: 1-4.

Saire, J.C., and K. Panford-Quainoo. 2020. Twitter interaction to analyze Covid-19 Impact in Ghana, Africa from March to July. https://arxiv.org/pdf/2008.12277.pdf. Accessed 29 Sept 2020.

Scott, J. 1985. Weapons of the weak: Everyday forms of peasant resistance. New Haven: Yale University Press.

Shepler, S. 2016. "We know who is eating the Ebola money!": Corruption, the state, and the Ebola response. Anthropological Quarterly (Special Issue: Producing Ebola) 90 (2): 457-480.

Shoman, H., E. Karafillakis, and S. Rawaf. 2017. The link between the West African Ebola outbreak and health systems in Guinea, Liberia and Sierra Leone: A systematic review. Globalization and Health 13 (1): 1-22.

Sikor, T., and D. Müller. 2009. The limits of state-led land reform: An introduction. World Development 37 (8): 1307-1316.

Sierra Network Salone. 2020. Inter-district partial lockdown and curfew (9pm-6pm) extended till further notice. 24 April. https://snradio.net/inter-district-partial-lockdown-and-curfew-9pm-6am-extendedtill-further-notice/. Accessed 30 Apr 2020.

Smith, J. 2019. Overcoming the 'tyranny of the urgent': Integrating gender into disease outbreak preparedness and response. Gender and Development 27 (2): 355-369.

Strong, A., and D.A. Schwartz. 2016. Sociocultural aspects of risk to pregnant women during the 20132015 multinational Ebola outbreak in West Africa. Health Care for Women International 37 (8): 922-942.

Vanguard. 2020. Senegal extends state of emergency for coronavirus. 7 April. https://www.vanguardng r.com/2020/04/senegal-extends-state-of-emergency-for-coronavirus/. Accessed 30 Apr 2020.

WHO. 2020a. Sierra Leone institutes additional measures in preparedness to prevent and respond to COVID-19. 17 March [Online]. Available from: https://www.afro.who.int/news/sierra-leone-insti tutes-additional-covid-19-preparedness-and-response-measures. Accessed May 192020.

WHO. 2020b. Safe Ramadan practices in the context of the COVID-19. Interim Guidance, Reference Number: WHO/2019-nCoV/Ramadan/2020.1.

Wilkinson, A., and J. Fairhead. 2017. Comparison of social resistance to Ebola response in Sierra Leone and Guinea suggests explanations lie in political configurations not culture. Critical Public Health 27 (1): 14-27.

Wilkinson, A., and M. Leach. 2014. Briefing: Ebola-myths, realities, and structural violence. African Affairs 114 (454): 136-148.

Wilkinson, A., M. Parker, F. Martineau, and M. Leach. 2017. Engaging 'communities': Anthropological insights from the West African Ebola epidemic. Philosophical Transactions of the Royal Society B 372: $1-7$.

Woo, J.J. 2020. Policy capacity and Singapore's response to the COVID-19 pandemic. Policy and Society 39 (3): $345-362$.

Publisher's Note Springer Nature remains neutral with regard to jurisdictional claims in published maps and institutional affiliations. 